\title{
Dynamic X-ray micro-CT insights of the recovery of ore bodies in presence of clay
}

Jan Dewanckele ${ }^{1}$, Wesley De Boever ${ }^{2}$, Andreas Grießer ${ }^{3}$, Yanhong Wang ${ }^{4}$ and Fangli Meng 5

${ }^{1}$ TESCAN, Belgium, ${ }^{2}$ Tescan, Belgium, ${ }^{3}$ Math2Market GmbH, United States, ${ }^{4}$ Central South University, China, China (People's Republic), ${ }^{5}$ TESCAN China, China (People's Republic)

Clay minerals such as bentonite are widely present in various ore bodies, mainly as gangue minerals. For mining industries, the processing of those ore bodies is very challenging as the presence of clay results in poor flotation performance. The coating of the clay on the valuable ore minerals reduces the recovery of those minerals. The presence and addition of salt ions in water may have a significant effect on the slime coatings (Chen and Peng, 2018) and pulp rheology (Huang et al., 2020) enhancing for example chalcopyrite recovery (Jeldres et al., 2019).

In order to better understand the above-described complex interactions of clay, salts and water, an in situ experiment was performed in a TESCAN CoreTOM, enabling 4D visualization and better understanding of the clay behaviour. By using high speed X-ray micro-CT (dynamic CT) we were able to visualize the flocculation pattern, in three dimensions as a function of time, of bentonite clay in fresh water, $\mathrm{NaCl}$ solution, and $\mathrm{KCl}$ solution. In this study, 8 g bentonite was mixed with $2 \mathrm{~g}$ chalcopyrite in 1) $50 \mathrm{~mL}$ DI water, 2) $50 \mathrm{ml} \mathrm{DI}$ water $+1 \mathrm{~mol} / \mathrm{L} \mathrm{NaCl}$ and 3) $50 \mathrm{ml}$ DI water $+1 \mathrm{~mol} / \mathrm{L} \mathrm{KCl}$. The suspension was stirred for $15 \mathrm{~min}$ before subsampling. Micro-CT was acquired using scans with a continuous speed of $5.8 \mathrm{sec} /$ rotation $\left(0^{\circ}-360^{\circ}\right)$ and a voxel size of $15 \mu \mathrm{m}$. In total 100 uninterrupted rotations were acquired with 400 projections each. Both temporal and spatial resolution was sufficient to visualize and analyse the dynamics in three dimensions showing clear differences between the systems. Motions of particles where analysed using the Software GeoDict.

Along with playing a critical role in soil stability and mining applications, bentonite is a widely used clay in many industrial products such as paints, ceramics, drilling fluids, etc. Although commonly used, the bentonite-water systems are not yet fully understood. The authors hope that these initial experiments may open doors towards many other applications and a better understanding of these, and similar, dynamic interactions.

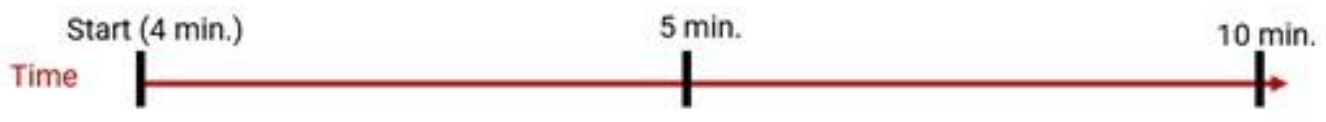

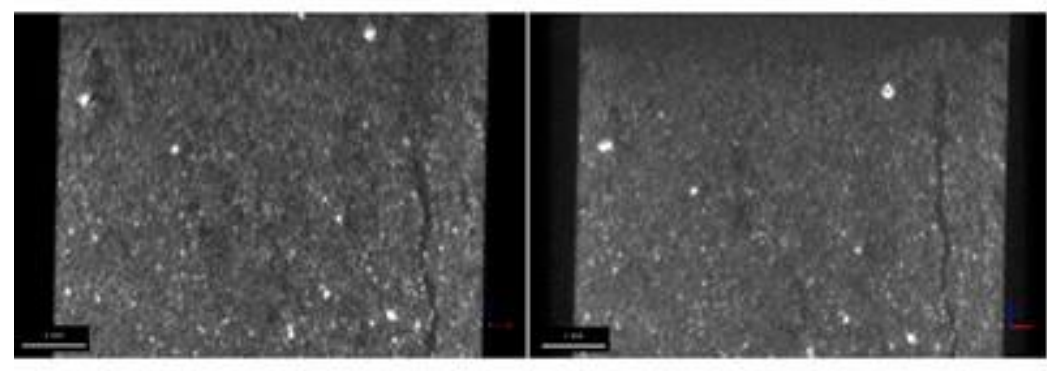

$5.8 \mathrm{~s}$ scan

5.8 s scan

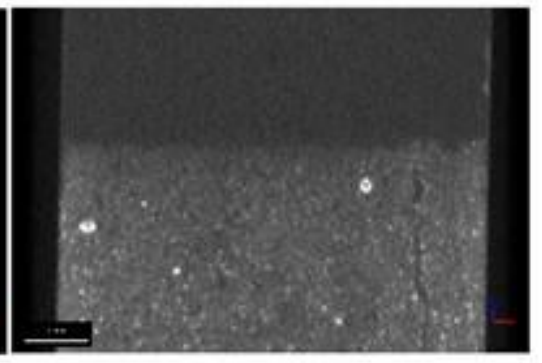

5.8 s scan

Figure 1. Reconstructed micro-CT slides at three time steps (out of 100) of the flocculation of a mixture of bentonite and chalcopyrite in the presence of $\mathrm{NaCl}$ and water. This flocculation process starts within minutes with a formation of a clear concentration front.

\section{References}

Huang, L., Song, S., Gu, \&Wang, Y. (2020, September 10). The interaction between cations in saline water and calcium bentonite in copper flotation. https://doi.org/10.1007/s42461-020-00297-4 
Jeldres, R. I., Uribe, L., Cisternas, L. A., Gutierrez, L., Leiva, W. H., \& Valenzuela, J. (2019, March 15). The effect of clay minerals on the process of flotation of copper ores - A critical review. Applied Clay Science, Vol. 170, pp. 57-69. https://doi.org/10.1016/j.clay.2019.01.013

Xumeng Chen \& Yongjun Peng (2018): Managing clay minerals in froth flotation - critical review, Mineral Processing and Extractive Metallurgy Review. Vol.39, pp.289-307. https://doi.org/10.1080/08827508.2018.1433175 